\title{
Parenting Practices and Behavioral Problems among Adolescents' of Parents with Psychopathology: Role of Adolescents' Coping as Moderator": parenting Practices and Behavioral problems
}

\author{
Fazaila Sabih \\ Riphah International University, Pakistan \\ fazaila.sabih@riphah.edu.pk
}

Anis ul Haque

National university of Modern Languages, Islamabad, Pakistan

ahaque@numl.edu.pk

\section{Sana Younas}

Riphah International University, Pakistan

sanayounasmphil@gmail.com

\author{
Asia Mushtaq \\ National university of Modern Languages, Islamabad, Pakistan \\ asmushtaq@numl.edu.pk
}

\begin{abstract}
Numerous studies suggest that symptoms of mental illness in parents become reflected in family and parent-child interactions, affecting the nature and quality of caregiving and, in turn, both short- and long-term child outcomes. Given the paucity of research in this area in Pakistan, present study aims to examine differences in parenting practices and behavioral problems among adolescent children of parents with psychopathology and without psychopathology. It also explores moderating role of adolescents' coping on the relationship between parenting practices and behavioral problems. Sample included 348 parents and their adolescent children divided into two groups: Parents with Psychopathology and without Psychopathology. Alabama Parenting Questionnaire, Youth Self Report, and Brief COPE were used for data collection. Results indicated that adolescent children having parents with psychopathology have elevated levels of behavioral problems as compared to adolescent children of parents without psychopathology. Results of moderation analyses revealed that problemfocused coping, positive coping, and religious coping mitigated the potential impact of negative parenting practices on externalizing problems whereas denial exacerbated this relationship. The implications are discussed for implementation of effective preventive interventions with at risk families and children.
\end{abstract}

Keywords. Parenting practices, Behavioral Problems, Adolescents, Parents with Psychopathology, Coping 


\section{Introduction}

www.techniumscience.com

Parental psychopathology is now considered to be the important point of intervention for at-risk children and youth. Psychopathologists are not only trying to uncover underlying causes of parental psychopathology but also trying to minimize its deleterious effects on the psychological functioning and development of children. Most of the research in the field of psychopathology is focusing on identification, prevention and intervention of adverse social and psychological outcomes in children of parents with psychopathology (Christiansen, Anding, Schrott, \& Rohrle, 2015; Fraser, James, Anderson, Lloayd, \& Judd, 2006; Gladstone \& Beardslee, 2009; Siegenthaler, Munder, \& Egger, 2012). The present study attempts to explore moderating role of adolescents' coping and effortful control on the relationship between parenting practices and behavioral problems among adolescents having parents with psychopathology.

Goodman and Gotlib (1999), in a comprehensive review proposed a model that gives a useful framework for understanding both risk and resilience processes among children of parents with psychopathology. They identified multiple mediating and moderating variables. Mediators are the mechanisms of risk that result from parental mental illness. These are the variables that place the child at risk and eventually lead to psychopathology. Moderating factors are the variables that are not directly linked with parental psychopathology, but can aggravate the child outcomes. The important child characteristics in the Goodman and Gotlib (1999) model include child's temperament, gender, intellectual and social-cognitive abilities (such as interpersonal skills and social competence), problems solving abilities and coping skills. In their review, the authors have highlighted the lack of empirical evidence regarding the role of child characteristics as moderators between contextual factors and child outcomes.

Given that parenting practices are strong predictors of later children maladjustment. It is now widely recognized that children are not just considered as subservient recipients of the contextual factors, they play very important role in their socialization processes. Thus, this research study intends to examine the possible moderating role of adolescents' personal factors like coping and effortful control on the relationship between different forms of parenting practices and behavioral problems among adolescents having parents with psychopathology. Considering how these two adolescent characteristics interact with parenting to predict behavioral problems may be particularly important because these two characteristics may serve to amplify or mitigate the effects of parenting practices in distinct ways. These factors are highly neglected in research; their potential importance underscores the need to study these variables. To researcher's knowledge, up till now, no study has concentrated on exploring the moderating role of these two potential variables between the relationship of parenting practices and behavioral problems among adolescents particularly with reference to high risk group.

Coping. Coping involves utilizing various cognitive, emotional, and behavioral strategies while dealing with daily stressors/problems. Coping include all those covert and overt repertoires of behavior through which individuals can actively alleviate, prevent, or respond to stress. Coping refers to "Constantly changing cognitive and behavioral efforts to manage specific external and /or internal demands that are appraised as taxing or exceeding the resources of the person" (Lazarus \& Folkman, 1984, p.141).

Coping strategies are typically viewed as being either cognitive or behavioral in nature. According to Ebata and Moos (1991) cognitive coping strategies include activities such as logical analysis of the stressor, positive reappraisal, cognitive avoidance, and resigned acceptance. Behavioral coping strategies include activities such as guidance/support seeking, problem solving, seeking alternative rewards, and emotional discharge. Coping strategies are broadly divided into two groups: active or problem-focused coping (directly acting on/dealing 
with the stressor or the cause of stress) and passive or emotion-focused coping (Regulating emotional states that result from the stressful event) [Compas, 2001].

It is widely acknowledged that adolescence is characterized by numerous developmental changes that may tax emotional and cognitive resources. Adolescents' ability to cope efficiently with stress is considered as an essential part of resilience and is vital in influencing patterns of positive growth and development (Werner, 1989). Diverse psychosocial maladjustment outcomes are frequently documented in the transitional period of adolescence (Rutter \& Smith, 1995). Therefore, the identification of risk and protective factors in adolescents who are experiencing adjustment problems is necessary to facilitate and foster healthy psychosocial adjustment.

Coping strategies can act as protective or risk factors regarding healthy adjustment and psychological well-being of adolescents (Masten, Best, \& Garmezy, 1990; Seiffge-Krenke, 1995). Earlier studies have documented that problem-focused coping is linked with healthy psychosocial adjustment, better psychological well- being as well as decreased internalizing and externalizing symptoms among adolescents. On the contrary, emotion-focused coping that is indicative of emotional dysregulation is related to greater emotional, behavioral, and social maladjustment related issues (Braun-Lewensohn et al., 2009; Windle \& Windle, 1996).

Moderating Role of Coping. Numerous prospective, longitudinal studies have established that parental psychopathology is a risk factor for emotional and behavioral problems among adoelscents (Anderson \& Hammen, 1993; Burstein, Ginsberg, \& Tein, 2010; Weissman et al., 1997, 2006; Williamson, Birmaher, Axelson, Ryan, \& Dahl, 2004). At the same time, there are many children who grow up in homes with parental psychopathology but do not develop impairments. It is in fact the balance of risk factors and protective resources that determines outcome (Beardslee, 2002; Hammen, 1991). Since the relationship between parental psychopathology and adverse outcomes in offspring is not apparent in all children, the researchers started to explore the variables that may temperate this relationship (Burt et al., 2005; Suveg, Shaffer, Morelen, \& Thomassin, 2011). Studies on genetic, environmental, and individual risk factors for psychological problems also point to a remarkable finding that not all individuals develop the disorder when exposed to risk factors. Consequently, the current research has shifted the focus of attention towards the identification of those potential protecting factors that can act as sources of resilience in the face of known risk.

On the basis of extensive aforementioned theoretical findings, it can be concluded that parental psychopathology is associated with poor parent-child interactions and has deleterious effect on parenting. Parenting is an important and significant mechanism through which parental psychopathology may have negative impact on children (Goodman \& Gotlib, 1999, 2002). Hence, it is important to identify protective and risk factors for planning and developing evidence-based preventions and interventions. Utilization of effective coping strategies can be an essential resource in developing resilience in individuals who are living under chronic stress (e.g., having a parent with psychopathology).

Given that parenting practices of parents with psychopathology are a risk factor for behavioral problems, current study uniquely contributes to the existing literature by focusing on an important moderator (adolescents' coping) that has received little attention thus far. The studies exploring the role of moderators in the relation between parenting practices and youth problems, adolescents' coping is one important factor that has been ignored. Overall, research has demonstrated fairly consistent associations between coping and parenting (Eisenberg, Cumberland, \& Spinrad, 1998; Kliewar, Sandler, \& Wolchik, 1994; Meesters \& Muris, 2004; Smith et al., 2006; Zimmer- Gembeck \& Locke, 2007) as well as parenting and behavioral problems (Darling \& Steinberg, 1993; Frick et al., 1999; Gaertner et al., 2010; Lansford et al., 2003; Maccoby \& Martin, 1983) but coping as moderator in the association between parenting 
and behavioral problems has received very little attention. Examining the interaction between these variables is important given that it provides information about which coping strategies might cushion the negative impact of dysfunctional parenting on behavioral problems among adolescents in this high risk population especially in local context.

Research has demonstrated that adolescents' adaptive coping strategies buffer the negative effects of stressful events and consequently foster healthy psychological adjustment (Compas et al., 2001; Grant et al., 2006). Studies exploring the moderating role of coping in adolescents found that positive reappraisal moderated the relationship between perception of stress and depression (Gomez, 1998; Kraaji et al., 2003; Rogers, Mary, \& Holmbeck, 1997). $\mathrm{Ng}$ and Hurry (2011) found that use of problem solving and rejecting non-productive coping strategies emerged as protective factors against depression in the presence of stress among adolescents.

After reviewing the literature, our study aims to examine the moderating role of adolescent coping and effortful control on the association between parenting practices and behavioral problems among high risk group of adolescents. Considering how these two adolescent characteristics interact with parenting to predict behavioral problems may be particularly important because these two characteristics may serve to amplify or mitigate the effects of parenting practices in distinct ways. The inclusion of coping and effortful control as moderators in the current study will also help to identify the differential effect of these two variables on the relationship between parenting practices and adolescent outcomes such as behavioral problems.

\section{Method Hypotheses}

1. Coping strategies (avoidant coping, problem-focused coping, positive coping, religious coping and denial) of adolescents will moderate the association between positive involvement/parenting and externalizing problems.

2. Coping strategies (avoidant coping, problem-focused coping, positive coping, religious coping and denial) of adolescents will moderate the association between negative/ineffective discipline and externalizing problems.

\section{Sample}

The sample of the study consisted of 348 families (one parent and their adolescent child) divided into two groups: clinical group (parents with psychopathology) and control group (parents without psychopathology). The clinical group (parents with psychopathology) include 173 families: one parent either father or mother (Fathers $=74 \&$ Mothers $=99)$ and their adolescent children. Among 173 parents, 107 (61.8\%) were having Major Depressive Disorder (MDD) and $66(38.2 \%)$ were having Schizophrenia. There were $34(31.8 \%)$ fathers and 73 (68.2\%) mothers in MDD group while there were 40 (60.6\%) fathers and 26 (39.4\%) mothers in Schizophrenia group. One adolescent was randomly selected from each family resulting in total number of 173 adolescents. Among adolescents $82(47.4 \%)$ were boys and 91(52.6\%) were girls. The mean age of parents was $42.66(S D=3.86)$ and the age range of the adolescents was $12-18$ years $(M=15.14, S D=1.97)$. The family history of mental illness was present in 66 $(38.2 \%)$ patients, whereas $107(61.8 \%)$ patients were not having any history of mental illness. Almost $49 \%$ of parents were having up to 3 children and 51\% were having more than 3 children.

Parents with psychopathology were selected from psychiatric units of Rawalpindi and Islamabad. The participants were selected through purposive sampling technique. The sample was diagnosed according to the diagnostic criteria of DSM- 5 by the respective psychiatrist and 
clinical psychologists. Detailed case history interviews were conducted by trained clinical psychologists. Initially patients were referred by the psychiatrists according to required inclusion criteria. Then all patients who met eligibility criteria were further evaluated through psychological case history form to get detailed information about their psychiatric illness as well as to confirm the diagnosis. Diagnostic reliability of psychiatrist-referred sample was assessed by two clinical psychologists independently who were blind to clinical status of the patients. Cohen's kappa was calculated to determine the agreement between the two psychiatric records for the diagnoses of Major depressive Disorder and Schizophrenia. There was strong agreement between the two raters on diagnoses of Major depressive Disorder ( $\square=0.91, p<$ $.001)$ and Schizophrenia $(\square=0.88, p<.001)$.

The control group (parents without psychopathology) include 175 families one parent (either father or mother, Fathers $=69(39.4 \%) \&$ Mothers $=106(60.6 \%)$ and their adolescent children. One adolescent was randomly selected from each family resulting in total number of 175 adolescents. Among adolescents 81 (53.7\%) were boys and 94 (46.3\%) were girls. The control group was selected from different institutes and organizations of Rawalpindi and Islamabad city. The selected participants were then screened with the help of psychological case history form for any possible indication of medical or psychiatric illness. $47 \%$ of parents were having up to 3 children and 53\% were having more than 3 children. The participants were selected through purposive sampling technique.

Ethical Statement: This manuscript is part of first author's Ph.D thesis. Moreover, Informed consent has been taken from all study participants and concerned organizations

\section{Instruments}

Mini Mental State Examination. The Mini-Mental State Examination (MMSE) Urdu version (Awan et al., 2015) was used in the present study to assess cognitive impairment in the patients with schizophrenia. MMSE is a brief, standardized screening tool used to measure impairment in cognitions (Folstein, Folstein \& McHugh, 1975). The MMSE has 11 simple questions categorized into 7 cognitive domains. These domains include "orientation to time", "orientation to place", "registration of three words", "attention and calculation", "recall of 3 words", "language, and visual construction". Total score is 30 , the classification of impairment levels is done as none (24-30); mild (18-23) and severe (0-17) and the cutoff point is 24 . Based on the screening of MMSE only those patients with schizophrenia were included in the study who scored above the cutoff point. Low score indicate presence of cognitive impairment.

Alabama Parenting Questionnaire (APQ) Parent and Child Form. APQ (Shelton, Frick, \& Wootton, 1996) Urdu version (Mushtaq, 2015) was used to examine parenting practices. Both parent and child forms are available and in the present research both forms were used. Cross-reporter measures of parenting practices were used to minimize the effects of reporter bias and shared method variance. The original APQ is a self-report measure of parenting and has 42 items. Both child and parent forms are scored on a "5-point Likert scale" ( $1=$ "never" to $5=$ "always"). Higher scores indicate more use of that particular parenting dimension. APQ has good psychometric properties including internal consistency, convergent validity with other forms of the questionnaire (Shelton et al., 1996), and good criterion validity (Dadds, Maujean, \& Fraser, 2003; Frick et al., 1999; Shelton et al., 1996).

Youth Self Report (YSR). To assess the behavioral problems among adolescents, YSR Urdu translation by Khan and Avan (2014) was used. YSR (Achenbach \& Rescorla, 2001) is one component of ASEBA (Achenbach System of Empirically Based Assessment) - a multiaxial behavioral assessment procedure for behavioral and emotional problems in adolescents. YSR is a self-report measure and comprises of 118 questions, scored on a "3-point Likert scale" 
( 0 = "absent", 1 = "occurs sometimes", 2 = "occurs often"). The YSR is used only with children 11-18 years. The "Externalizing Problems" scale includes "Rule-Breaking Behavior" and "Aggressive Behavior" subscales. The YSR has satisfactory internal consistency and test re-test reliability. The alpha value for the Internalizing scale is .91 and for the externalizing scale is .92 (Achenbach \& Rescorla, 2001). The Youth Self Report (YSR) has also acceptable content validity, convergent validity, and construct validity (Achenbach \& Rescorla, 2001).

Brief COPE. The Brief COPE (Carver, 1997), Urdu version by Akhtar (2005) was used to assess the coping of adolescents. It is a shorter version of COPE Inventory (Carver, Scheier, \& Weintraub, 1989) and has good psychometric properties. It consists of "28 items". The Brief COPE has "14 subscales" and items are scored on a "4-point Likert format" -" 1 = Never", " 2 = Very less", " 3 = Sometimes", and " 4 = A lot". Brief COPE (Urdu version) has been extensively used in local context and has well established psychometric properties (Aslam \& Kamal, 2015; Fatima \& Tahir, 2013; Nazir \& Mohsin, 2013). In the present study, the 14 subscales were classified into five subscales: "Avoidant Coping", "Problem-Focused Coping", "Positive Coping", "Religious Coping", and "Denial Coping" as previously categorized (Nazir \& Mohsin, 2013). On each subscale high score shows more use of that particular coping strategy and vice versa.

\section{Procedure}

The data of the study was collected from different psychiatric units/clinics of Rawalpindi and Islamabad city. First of all, to get permission for data collection, the concerned hospital authorities were approached and purpose of study was explained to them. Then, the patients were approached through psychiatrists. Initially patients were referred by the psychiatrists according to required inclusion criteria. Then patients were administered psychological case history form by psychologists to get in-depth details about past and present history of their psychiatric illness and to further confirm the diagnosis and final diagnosis was made according to the diagnostic criteria of DSM-5. Patients who fulfilled the inclusion criteria were selected for instrument administration. Only those patients were included who consented to participate in the study. Before the administration of all study measures, participants were explained the purpose of study. Both verbal and written consent was taken from all the patients and confidentiality was assured. The research instruments and demographic information sheets were individually administered to the participants. Then adolescents of parents with psychopathology were approached with the consent of their parents. Adolescents also gave their consent. Data from adolescents was collected in hospital setting as well as at their homes. The same standard procedure was applied to the adolescents as to their parents. Adolescents took 35-45 minutes to complete the instruments. Anonymity of the participants was maintained.

The control group sample (parents with no psychopathology) was selected from the different institutes and organizations of the city Rawalpindi and Islamabad. Same standard procedure applied to the clinical group was followed with control group. The scales were administered individually in the similar testing situations. The sitting arrangement and other environmental variables were made identical throughout the study. In the context of Pakistani culture, it is important to mention that researchers face multiple difficulties to conduct a study in the clinical setting. In Pakistan, still stigma and isolation is attached with mental health disorders. It is quite difficult to obtain permission and consent from patients and caregivers because of trust and confidentiality related issues. Patients don't feel comfortable to disclose their personal information. The lack of funding, reluctant attitude of caregivers and patients, and at times uncooperative attitude of the clinicians limit the opportunity for increased sample size which was also the case in the present study. 
Analysis Plan

www.techniumscience.com

The Data was analyzed through SPSS and results were compiled. Parenting practices were assessed through MANCOVA that yielded a significant main effect. Pillai's trace in MANCOVA showed a significant effect of type of illness on parenting practices, $V=0.459, F$ $(2,341)=33.81, p<.001$. Subsequent univariate analyses (ANCOVAs) revealed a significant main effect of parenting practices. Bonferroni posthoc analyses revealed that parents with psychopathology (MDD \& Schizophrenia) scored low on positive involvement/parenting and scored higher on negative/ineffective discipline and deficient monitoring than parents without psychopathology. Externalizing problems were assessed through Pillai's trace in MANCOVA for the adolescent reported behavioral problems yielded a significant effect, $V=0.189, F(2$, $341)=17.761, p<.001$. Subsequent univariate analyses (ANCOVAs) revealed significant main effects of externalizing problems. Bonferroni posthoc analyses revealed that adolescents having parents with psychopathology significantly scored higher on externalizing problems than adolescents having parents without psychopathology.

Moderation analyses were also computed by following the procedure recommended by Hayes and Matthes (2009) through Process Macro in SPSS. It was hypothesized that coping strategies (problem-focused coping, positive coping, religious coping and denial) of adolescents will moderate the association between negative/ineffective discipline and externalizing problems. The results of moderation analyses indicated that problem-focused coping, positive coping and denial moderated the association between negative/ineffective discipline and externalizing problems. The findings are presented below in tables 1-4.

Table 1

Moderating Effect of Problem-focused Coping on the Relationship between Positive Involvement/Parenting and Externalizing Problems among Adolescents ( $n=173)$.

Externalizing Problems

Predictors $\Delta \mathrm{R}^{2} \quad \beta$

Step 1

$.38 * * *$

Control Variables ${ }^{\text {a }}$

Step 2

$.16^{* * *}$

Positive Involvement/Parenting

$-.34 * * *$

Problem-focused Coping

$-.28 * * *$

Step 3

$.05^{* * *}$

Positive Involvement/Parenting x Problem-

$.31 * * *$

focused Coping

Total $\mathrm{R}^{2}$

$.59 * * *$

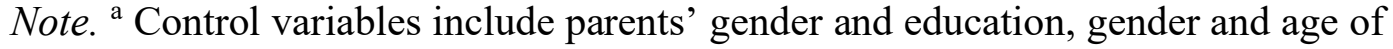
adolescents, duration of parental illness. 
$* * * p<.001$

Table 1 shows the results of moderation analysis which illustrates significant interaction between independent and moderator variables. The results indicated that positive involvement/parenting $\times$ problem-focused coping interaction produced a significant change in $\mathrm{R}^{2}$ for adolescents' externalizing problems $\left\{F(8,164)=17.73, \Delta R^{2}=.05, p<.001\right\}$ indicating that the relationship between positive involvement/parenting and externalizing problems is moderated by problem-focused coping. The interaction effect is further illustrated in Figure (2).

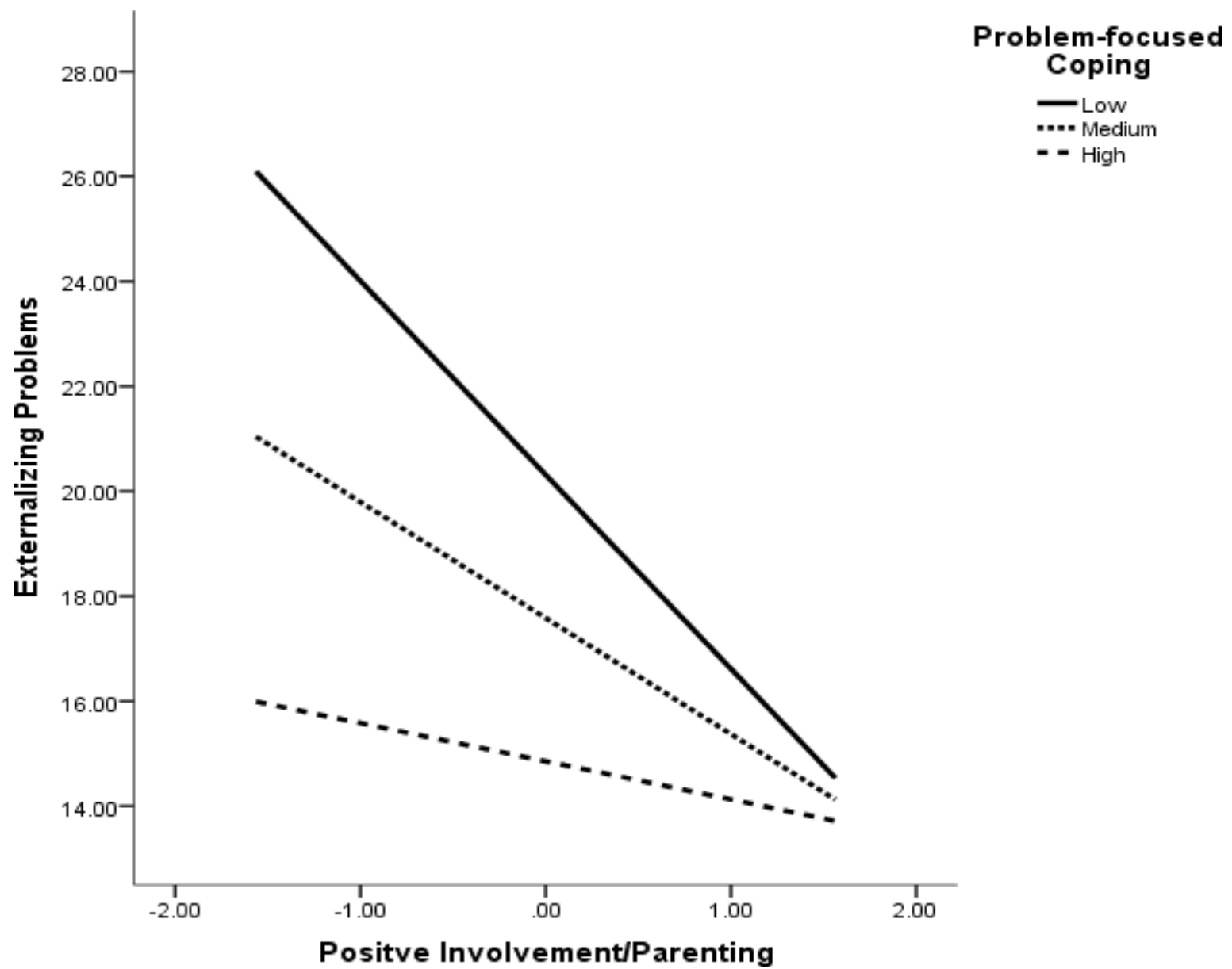

Figure 1. The moderating effect of problem-focused coping on the relationship between positive involvement/parenting and externalizing problems among adolescents.

The figure 2 illustrated that when problem-focused coping is high there is a nonsignificant relationship between positive involvement/parenting and externalizing problems, when problem-focused coping is low there is a strong significant negative relationship between positive involvement/parenting and externalizing problems. The results indicated that externalizing problems would be low under the condition of high positive involvement/parenting and high problem-focused coping. 
Table 2

Moderating Effect of Religious Coping on the Relationship between Positive Involvement/ Parenting and Externalizing Problems among Adolescents $(n=173)$

Externalizing Problems

Predictors

$\Delta \mathrm{R}^{2}$

$\beta$

Step 1

$.38 * * *$

Control Variables ${ }^{\text {a }}$

Step 2

$.15^{* * *}$

Positive Involvement/Parenting

Religious Coping

Step 3

$.01^{*}$

Positive Involvement/Parenting x Religious

$.48^{*}$

Coping

Total $\mathrm{R}^{2}$

$.54 * * *$

Note. ${ }^{\text {a }}$ Control variables include parents' gender and education, gender and age of adolescents, duration of parental illness.

$* p<.05, * * p<.01, * * * p<.001$

Results in table 2 demonstrated the significant interaction between independent and moderator variables. The results indicated that positive involvement/parenting $\times$ religious coping interaction produced a significant change in $\mathrm{R}^{2}$ for adolescents' externalizing problems $\left\{F(8,164)=4.93, \Delta R^{2}=.01, p<.05\right\}$ indicating that the relationship between positive involvement/parenting and externalizing problems is moderated by religious coping. The interaction effect is further demonstrated in Figure (3). 


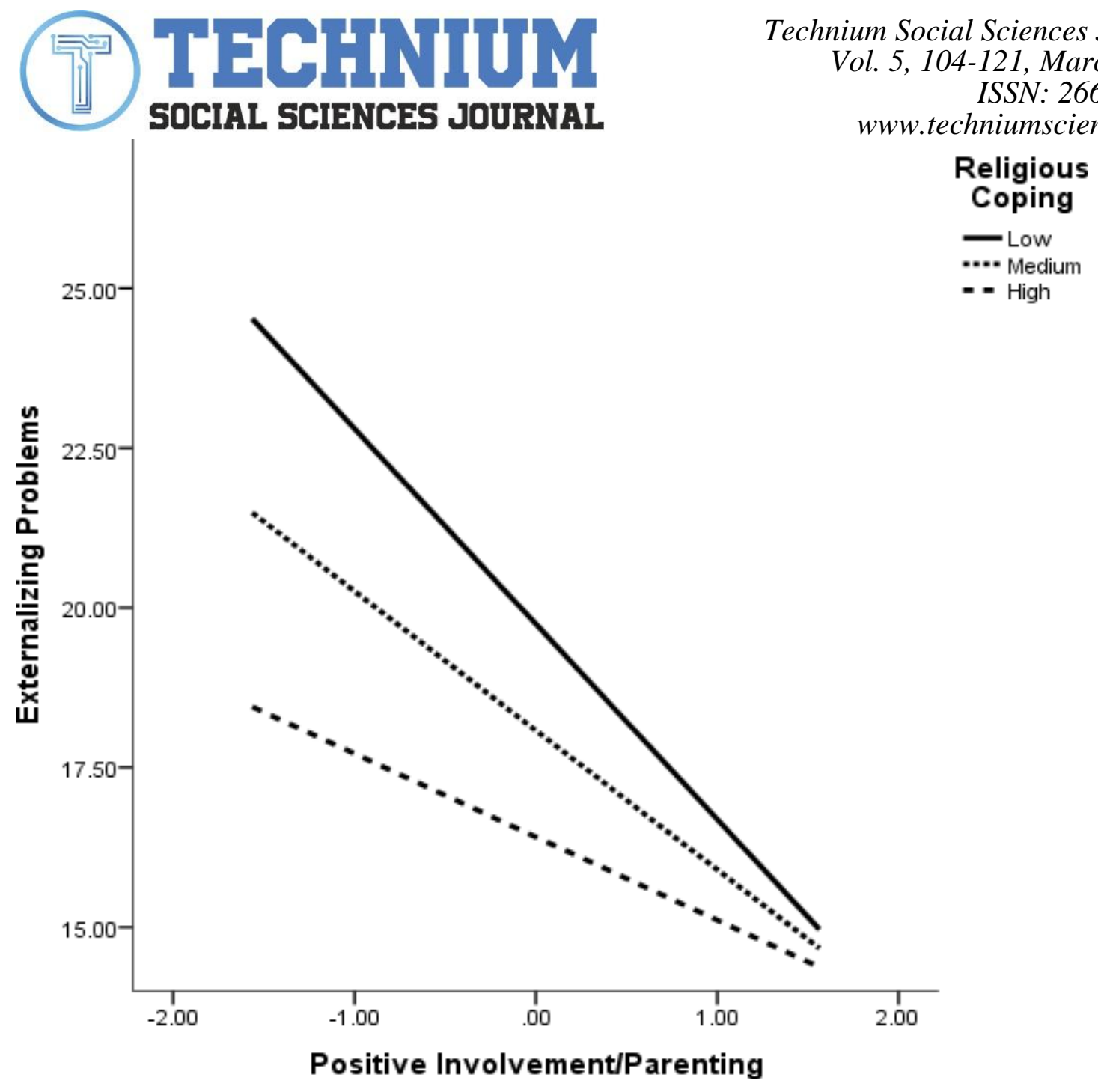

Figure 2. The moderating effect of religious coping on the relationship between positive involvement/parenting and externalizing problems among adolescents.

The figure 3 indicated that the relationship between positive involvement/parenting and externalizing problems would be relatively weaker when religious coping is high and relatively stronger when religious coping is low.

Table 3

Moderating Effect of Denial on the Relationship between Positive Involvement/Parenting and Externalizing Problems among Adolescents $(n=173)$.

Externalizing Problems

Predictors

$\Delta \mathrm{R}^{2} \quad \beta$

Step 1

$.38 * * *$

Control Variables ${ }^{\text {a }}$

Step 2

$.17 * * *$

Positive Involvement/Parenting

Denial 


\section{(2) TECHNIUM \\ SOCIAL SCIENCES JOURNAL}

Step 3
Technium Social Sciences Journal

Vol. 5, 104-121, March 2020

ISSN: 2668-7798

www.techniumscience.com

$.01 *$

Positive Involvement/Parenting x Denial

$-.35^{*}$

Total $\mathrm{R}^{2}$

$.56 * * *$

Note. ${ }^{\text {a }}$ Control variables include parents' gender and education, gender and age of adolescents, duration of parental illness.

${ }^{*} p<.05, * * * p<.001$

Table 3 displayed the significant moderating effect of denial on the relationship between positive involvement/parenting and externalizing problems among adolescents. The results indicated that interaction between independent and moderator variables produced a significant change in $\mathrm{R}^{2}$ for adolescents' externalizing problems $\left\{F(8,164)=3.90, \Delta R^{2}=.01, p<.05\right\}$. The interaction effect is further presented in Figure (3).

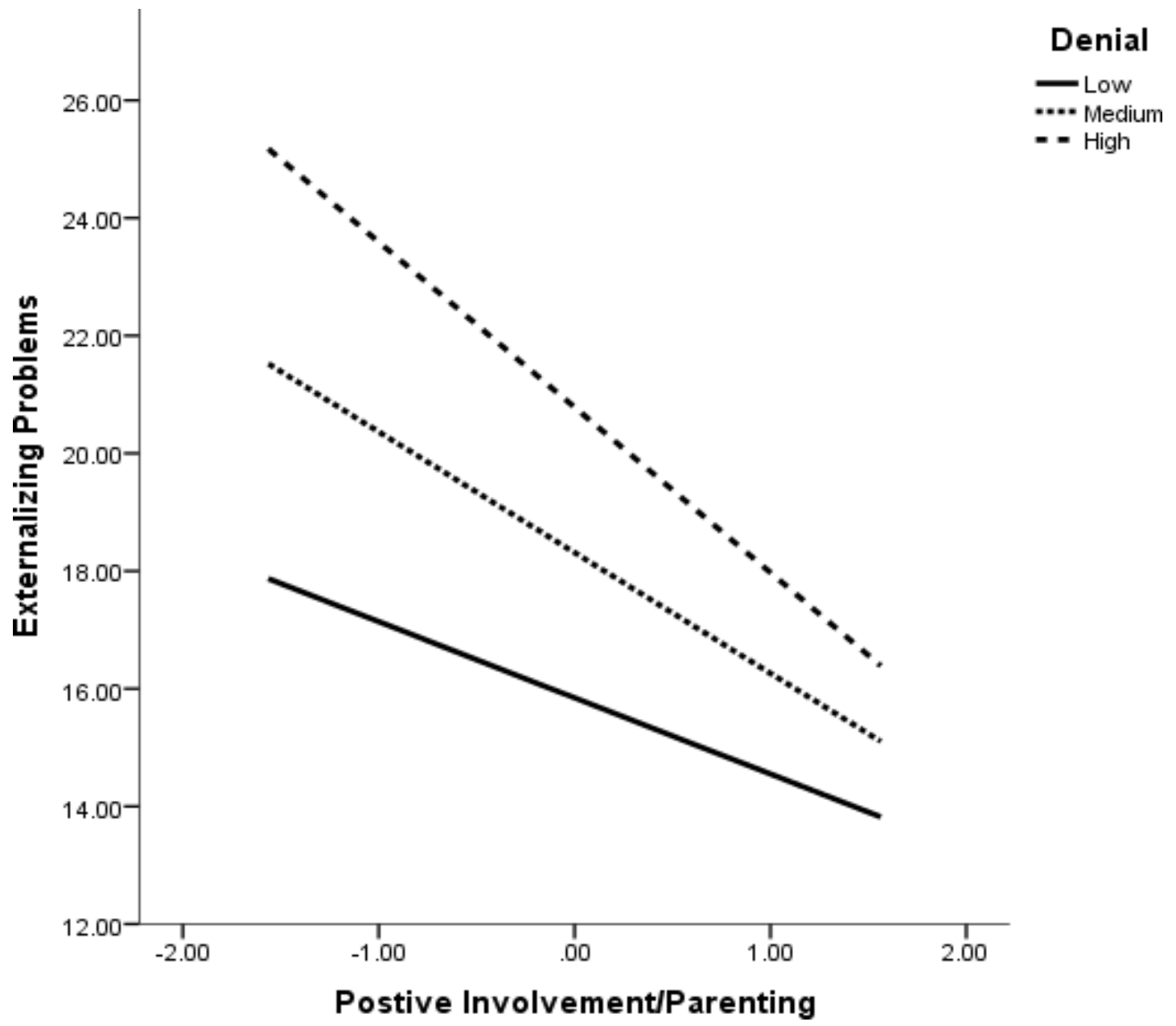

Figure 3. The moderating effect of denial on the relationship between positive involvement/parenting and externalizing problems among adolescents.

The figure 3 illustrated that externalizing problems would be high in case of low positive involvement/parenting and high denial and would be low in case of high positive involvement/parenting and low denial. 


\section{Table 4}

Moderating Effect of Positive Coping on the Relationship between Negative/Ineffective Discipline and Externalizing Problems among Adolescents ( $n=173$ ).

Externalizing Problems

Predictors

$\Delta \mathrm{R}^{2}$

$\beta$

Step 1

Control Variables ${ }^{\text {a }}$

Step 2

Negative/Ineffective Discipline

Positive Coping

Step 3

$.03 * *$

Negative/Ineffective Discipline $\times$ Positive Coping

Note. ${ }^{\text {a }}$ Control variables include parents' gender and education, gender and age of adolescents, duration of parental illness.

$* * p<.01, * * * p<.001$

Table 4 shows the results of moderation analysis which illustrates that negative/ineffective discipline $\times$ positive coping interaction produced a significant change in $\mathrm{R}^{2}$ for adolescents' externalizing problems $\left\{F(8,164)=10.22, \Delta R^{2}=.03, p<.01\right\}$ indicating that the relationship between negative/ineffective discipline and externalizing problems is significantly moderated by positive coping. The interaction effect is further exhibited in Figure (4). 


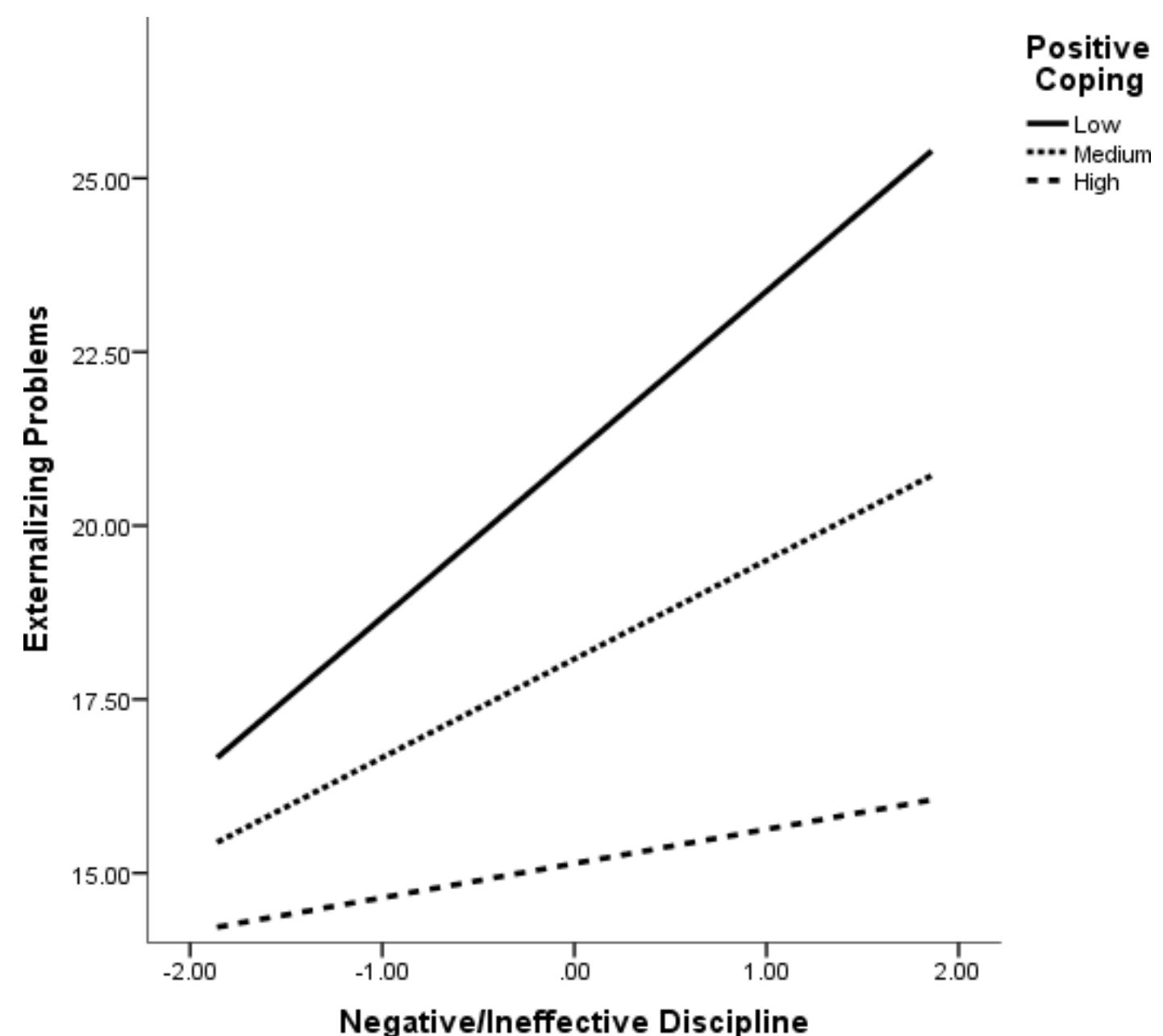

Figure 4. The moderating effect of positive coping on the relationship between negative/ineffective discipline and externalizing problems among adolescents.

The figure 4 illustrated that the relationship between negative/ineffective discipline and externalizing problems is mitigated in case of high positive coping as compared to low positive coping.

\section{Discussion}

This study explored the moderating role of coping strategies of adolescents on the relationship between parenting practices and behavioral problems among adolescents having parents with psychopathology. These findings are consistent with the previous studies as it is well documented in the literature that parental psychopathology has deleterious effect on parenting practices and these parents have significantly less adequate parenting skills and experience difficulties in executing their parenting role (Goodman \& Brumley, 1990; Jaser et al., 2008; Lovejoy et al., 2000). Mental illness regardless of diagnosis can impede their ability to perform parental role. The main issues for parents with mental illness center on their capability to deal with their mental illness as well as simultaneously carrying out the parenting 
duties and responsibilities. Negative parenting by such parents is either characterized by underinvolvement or over-involvement with their children as well as poor monitoring and ineffective discipline (Beardslee et al., 1998; Goodman \& Gotlib, 1999). Many studies have reported that parental depression and schizophrenia is associated with wide range of inept parenting behaviors including lack of involvement and responsiveness, intrusive, hostile and punitive parenting, more rejection and less nurturance as well as more use of poor monitoring, ineffective and negative discipline (Goodman, 1987; Kane \& Garber, 2009; Weissman \& Jensen, 2002; Willinger et al., 2002).

There is a noticeable absence of research analyzing the moderating role of coping strategies on the relationship between parenting practices and behavioral problems among adolescents. After having an extensive literature search, no literature was found on the said subject. Hence this study is an attempt to contribute to the existing literature by examining the moderating effect of coping strategies on the relationship between parenting practices and behavioral problems among adolescents. Due to lack of any empirical evidence, the hypotheses were formulated on the basis of related literature regarding moderating role of coping in stress - distress relationship. It was expected that problem-focused, religious and positive coping will act as buffer between the relationship of parenting practices and behavioral problems, whereas denial will exacerbate this relationship. Particularly, it was intended to identify which coping strategies may increase or decrease the effect of dysfunctional parenting practices in the sample of adolescents having parents with psychopathology.

Findings of the study exhibited that problem-focused coping moderated the relationship between all three aspects of parenting practices (positive involvement/parenting, negative/ineffective discipline and externalizing problems, whereas positive coping moderated the relationship between negative/ineffective discipline and externalizing problems. The denial moderated the relationship between two aspects of parenting practices (positive involvement/parenting and negative/ineffective discipline) and externalizing problems, whereas religious coping moderated the relationship only between positive involvement/parenting and externalizing problems among adolescents. The problem-focused coping, positive coping and religious coping attenuated this relationship, whereas denial exacerbated this relationship.

\section{Conclusion and Future Direction}

The present research highlights the role of two important coping strategies (problemfocused coping and positive coping) which may serve to mitigate the effects of dysfunctional parenting (such as negative/ineffective discipline) on externalizing problems among adolescents having parents with psychopathology. The findings also reveal that denial coping strategy may further exacerbate the effect of negative parenting on externalizing outcomes among adolescents. The findings further indicated that problem-focused coping, religious coping, and denial moderated the relationship between positive/involvement parenting and externalizing problems. The present study acts as a pioneering endeavor in identification of certain coping strategies for adolescents having parents with psychopathology in dealing with the stressful environment created by dysfunctional parenting practices. The future studies may extend these findings by further exploring this area of research and these coping strategies may be targeted for the intervention plans for children of parents with psychopathology. Interventions with adolescents might, on the basis of these findings should focus on increasing the use of adaptive coping strategies (such as positive coping, religious coping, and problemfocused coping) and reducing the use of maladaptive coping strategies (such as denial). Moreover, future studies may examine impact of parenting practices on other psychosocial 
outcomes such as social cognitive skills, intellectual abilities, academic achievement, socialemotional competence and social skills in children of this high risk population.

\section{References}

[1] Achenbach, T. M., \& Rescorla, L. A. (2001). Manual for ASEBA school-age forms and profiles. Burlington: Univeristy of Vermont, Research Center for Children, Youth, and Families.

[2] Akhtar, M. (2005). Coping strategies and its relationship with stress and time demands among university students (Unpublished M.Phil Thesis). National Institute of Psychology, Quaid-i-Azam University Islamabad.

[3] Anderson, C. A., \& Hammen, C. L. (1993). Psychosocial outcomes of children of unipolar depressed, bipolar, medically ill, and normal women: A longitudinal study. Journal of Consulting and Clinical Psychology, 61, 448-454.

[4] Aslam, N., \& Kamal, A. (2015) Coping Strategies as Predictors of Psychological Distress and Post Traumatic Growth among Flood Affected Individuals.

[5] Awan, S., Shahbaz, N., Akhtar, S. W., Ahmad, A., Iqbal, S., Ahmed, S., ... Wasay, M. (2015). Validation Study of the Mini-Mental State Examination in Urdu Language for Pakistani Population. The Open Neurology Journal, 9, 53-58. doi.org/10.2174/1874205X01509010053

[6] Beardslee, W. R. (2002). Out of the darkened room: When a parent is depressed: Protecting the children and strengthening the family. Boston: Little, Brown and Company.

[7] Beardslee, W. R., Versage, E. M., \& Gladstone, T. R. (1998). Children of affectively ill parents: A review of the past 10 years. Journal of the American Academy of Child \& Adolescent Psychiatry, 37, 1134-1141.

[8] Braun-Lewensohn, O., Celestin-Westreich, S., Celestin, L. P., Verleye, G., Verté, D., \& Ponjaert-Kristoffersen. (2009). Coping styles as moderating the relationships between terrorist attacks and well being outcomes. Journal of Adolescence, 32(3), 585-599. doi: 10.1016/j.adolescence.2008.06.003

[9] Burstein, M., Ginsburg, G. S., \& Tein, J. Y. (2010). Parental Anxiety and Child Symptomatology: An Examinzation of Additive and Interactive Effects of Parent Psychopathology. Journal of Abnormal Child Psychology, 38(7), 897- 909. doi.org/10.1007/s10802-010-9415-0

[10] Burt, K. B., Van Dulmen, M. H. M., Carlivati, J., Egeland, B., Sroufe, L. A., Forman, D. R., ... Carlson, E. A. (2005). Mediating links between maternal depression and offspring psychopathology: The importance of independent data. Journal of Child Psychology and Psychiatry, 46, 490-499. doi:10.1111/j.1469- 7610.2004.00367.x

[11] Carver, C. S., Scheier, M. F., \& Weintraub, J. K. (1989). Assessing coping strategies: A theoretically based approach. Journal of Personality and Social Psychology, 56(2), 267-283.

[12] Christiansen, H., Anding, J., Schrott, B., \& Röhrle, B. (2015). Children of mentally ill parents - a pilot study of a group intervention program. Frontiers in Psychology, 6, 1494. doi.org/10.3389/fpsyg.2015.01494

[13] Compas, B. E. (1987). Coping with stress during childhood and adolescence. Psychological Bulletin, 101, 393-403.

[14] Compas, B. E., Connor-Smith, J. K., Saltzman, H., Thomsen, A. H., \& Wadsworth, M. E. (2001). Coping with stress during childhood and adolescence: Problems, progress, 
and potential in theory and research. Psychological Bulletin, 127 (1), 87-127. doi: 10.1037/0033-2909.127.1.87

[15] Dadds, M. R., Maujean, A., \& Fraser, J. A. (2003). Parenting and conduct problems in children: Australian data and psychometric properties of the Alabama Parenting Questionnaire. Australian Psychologist, 38, 238-241.

[16] Darling, N., \& Steinberg, L. (1993). Parenting style as context: An integrative model. Psychological Bulletin, 113(3), 487-496.

[17] Ebata, A. T., \& Moos, R. H. (1991). Coping and adjustment in distressed and healthy adolescents. Journal of Applied Developmental Psychology, 12(1), 33-54. doi:10.1016/0193-3973(91)90029-4

[18] Ellis, L. K., \& Rothbart, M. K. (2001). Revision of the Early Adolescent Temperament Questionnaire. Poster presented at the 2001 Biennial Meeting of the Society for Research in Child Development, Minneapolis, Minnesota

[19] Fatima, S., \& Tahir, S. (2013). Comparison of Coping Strategies Used by Adolescents on State and Trait Anxiety. FWU Journal of Social Sciences, 7(2), 165-174.

[20] Folstein, M., Folstein, S. E., McHugh, P. R. (1975). "Mini-Mental State" a Practical Method for Grading the Cognitive State of Patients for the Clinician. Journal of Psychiatric Research, 12(3), 189-198.

[21] Fraser, C., James, E., Anderson, K., Lloayd, D., \& Judd, F. (2006).Intervention programs for children of parents with a mental illness: a critical review. International Journal of Mental Health Promotion, 8, 9-20. doi:10.1080/14623730.2006.9721897

[22] Frick, P. J., Christian, R. C., \& Wootton, J. M. (1999). Age trends in the association between parenting practices and conduct problems. Behavior Modification, 23, 106-128.

[23] Gaertner, A. E., Fite, P. J., \& Colder, C. R. (2010). Parenting and Friendship Quality as Predictors of Internalizing and Externalizing Symptoms in Early Adolescence. Journal of Child and Family Studies, 19, 101-108. doi:10.1007/s10826-009-9289-3

[24] Garmezy, N. (1987). Stress, competence, and development: Continuities in the study of schizophrenic adults, children vulnerable to psychopathology, and the search for stress-resistant children. American Journal of Orthopsychiatry, 57, 159-174.

[25] Gladstone,T.R.G., \& Beardslee,W.R.(2009).The prevention of depression in children and adolescents: a review. Canadian Journal of Psychiatry 54,212-221.

[26] Gomez, R. (1998). Locus of Control and Avoidant Coping: Direct, Interactional and Mediational Effects on Maladjustment in Adolescents. Personality and Individual Difference, 24, 325-334. doi.org/10.1016/S0191-8869 (97)00161-X

[27] Goodman, S. H. (1987). Emory University project on children of disturbed parents. Schizophrenia Bulletin, 13, 411-423. doi: 10.1093/schbul/13.3.411

[28] Goodman, S. H., \& Brumley, H. E. (1990). Schizophrenic and depressed mothers: relational deficits in parenting. Developmental Psychology, 26, 31-39.

[29] Goodman, S. H., \& Gotlib, I. H. (1999). Risk for psychopathology in the children of depressed mothers: a developmental model for understanding mechanisms of transmission. Psychological Review, 106(3), 458-490. doi.org/10.1037/0033295X.106.3.458

[30] Goodman, S. H., \& Gotlib, I. H. (2002). Children of depressed parents: Mechanisms of risk and implications for treatment. Washington, DC: American Psychological Association.

[31] Hammen, C. (1991). Depression runs in families: The social context of risk and resilience in children of depressed mothers. New York: Springer-Verlag. 
[32] Jaser, S. S., Fear, J. M., Reeslund, K. L., Champion, J. E., Reising, M. M., \& Compas, B. E. (2008). Maternal Sadness and Adolescents' Responses to Stress in Offspring of Mothers with and without a History of Depression. Journal of Clinical Child and Adolescent Psychology, 37(4), 736-746. doi.org/10.1080/15374410802359742

[33] Kane, P. P., \& Garber, J. (2009). Parental depression and child externalizing and internalizing symptoms: Unique effects of fathers' symptoms and perceived conflict as a mediator. Journal of Child and Family Studies, 18(4), 465-472.

[34] Khan, B., \& Avan, B. I. (2014). Qualitative adaptation of child behavior problem instruments in a developing-country setting. Eastern Mediterranean Health Journal, 20(7), 450-458.

[35] Kliewer. W., Sandler, I., \& Wolchik, S. (1994). Family socialization of threat appraisal and coping: Coaching, modeling, and family context. In F. Nestmann \& K. Hurrelmann (Eds.), Social networks and social support in childhood and adolescence. Prevention and intervention in childhood and adolescence, (pp. 271-291). Oxford, England: Walter De Gruyter.

[36] Lansford, J. E., Criss, M. M., Pettit, G. S., Dodge, K. A., \& Bates, J. E. (2003). Friendship quality, peer group affiliation, and peer antisocial behavior as moderators of the link between negative parenting and adolescent externalizing behavior. Journal of Research on Adolescence, 13, 161-184.

[37] Lazarus, R. S., \& Folkman, S. (1984). Stress, Appraisal, and Coping. New York: Springer.

[38] Lovejoy, M. C., Graczyk, P. A., O’Hare, E., \& Neuman, G. (2000). Maternal depression and parenting behavior: A meta-analytic review. Clinical Psychology Review, 20(5), 561-592.

[39] Maccoby, E. E., \& Martin, J. A. (1983). Socialization in the context of the family: Parent-child interaction. In P. H. Mussen (Series Ed.) \& E. M. Hetherington (Vol. Ed.), Handbook of child psychology: Vol. 4. Socialization, personality, and social development (pp. 1-101) New York: Wiley.

[40] Masten, A., Best, K., \& Garmezy, N. (1990). Resilience and development: Contributions from the study of children who overcome adversity. Development and Psychopathology, 2, 425-444.

[41] Meesters, C., \& Muris, P. (2004). Perceived parental rearing behaviors and coping in young adolescents. Personality and Individual Differences, 37, 513-522.

[42] Nazir, A., \& Mohsin, H. (2013). Coping Styles, Aggression and Interpersonal Conflicts among Depressed and Non-Depressed People. Health Promotion Perspectives, 3(1), 80-89. doi: 10.5681/hpp.2013.010

[43] Ng, C. S. M., \& Hurry, J. (2011). Depression amongst Chinese adolescents in Hong Kong: An evaluation of a stress moderation model. Social Indicators Research, 100 (3), 499-516. doi: 10.1007/s11205-010-9626-3.

[44] Rogers, M. J., \& Holmbeck, G. N. (1997). Effects of interparental aggression on children's adjustment: The moderating role of cognitive appraisal and coping. Journal of Family Psychology, 11(1), 125-130. doi: 10.1037/0893- 3200.11.1.125

[45] Rutter, M., \& Smith, D.1. (995). Psychosocial Disorders in Young People. Chichester: Wiley.

[46] Seiffge-Krenke, I. (1995). Stress, coping, and relationships in adolescence. Mahwah, NJ: Erlbaum. 
[47] Shelton, K. K., Frick, P. J., \& Wootten, J. (1996). Assessment of parenting practices in families of elementary school-age children. Journal of Clinical Child Psychology, 25, 317-329.

[48] Siegenthaler, E., Munder, T., \& Egger, M. (2012). Effect of preventive interventions in mentally ill parents on the mental health of the offspring: systematic review and metaanalysis. Journal of American Academy of Child and Adolescent Psychiatry 51, 8-17. doi:10.1016/j.jaac.2011.10.018

[49] Smith, C. L., Eisenberg, N., Spinrad, T. L., Chassin, L., Morris, A. S., Kupfer, A., . . Kwok, O. M. (2006). Children's coping strategies and coping efficacy: Relations to parent socialization, child adjustment, and familial alcoholism. Development and Psychopathology, $\quad$ 18(2), 445-469.doi: 10.1017/S095457940606024X

[50] Suveg, C., Shaffer, A., Morelen, D., \& Thomassin, K. (2011). Links between maternal and child psychopathology symptoms: mediation through child emotion regulation and moderation through maternal behavior. Child Psychiatry and Human Development, 42, 507-20.

[51] Weissman, M. M., Warner, V., Wickramaratne, P., Moreau, D., \& Olfson, M. (1997). Offspring of depressed parents: Ten years later. Archive General Psychiatry, 54, 932940. doi:10.1001/archpsyc.1997.01830220054009

[52] Weissman, M. M., Warner, V., Wickramaratne, P., Nomura, Y., Warner, V., Pilowsky, D., \& Verdeli, H. (2006). Offspring of depressed parents: 20 years later. American Journal of Psychiatry, 163, 1001-1008.

[53] Werner, E. E. (1989). High risk children in young adulthood: A longitudinal study from birth to 32 years. American Journal of Orthopsychiatry, 59, 72-81.

[54] Williamson, D. E., Birmaher, B., Axelson, D. A., Ryan, N. D., \& Dahl, R. E. (2004). First episode of depression in children at low and high familial risk for depression. Journal of the American Academy of Child and Adolescent Psychiatry, 43, 291.297.

[55] Windle, M., \& Windle, R. C. (1996). Coping strategies, drinking motives, and stressful life events among middle adolescents: associations with emotional and behavioural problems and with academic functioning. Journal of Abnormal Psychology, 105, 551560.

[56] Zimmer-Gembeck, M. J., \& Locke, E. M. (2007). The socialization of adolescent coping behaviors: Relationships with families and teachers. Journal of Adolescence, 30, $1-16$.

[57] Kraaij, V., Garnefski, N., de Wilde, E. J., Dijkstra, A., Gebhardt, W., Maes, S. \& Ter Doest, L. (2003). Negative Life Events and Depressive Symptoms in Late Adolescence: Bonding and Cognitive Coping as Vulnerability Factors? Journal of Youth and Adolescence, 32(3), 185. doi:10.1023/A:1022543419747 